\title{
Down-Regulation of MT1-MMP Expression by the $\alpha 3$ Chain of Type IV Collagen Inhibits Bronchial Tumor Cell Line Invasion
}

\author{
Corinne Martinella-Catusse, Myriam Polette, Agnès Noel, Christine Gilles, \\ Pierre Dehan, Carine Munaut, Alain Colige, Laurette Volders, \\ Jean-Claude Monboisse, Jean-Michel Foidart, and Philippe Birembaut
}

INSERM U514, IFR 53, Unit of Cellular Biology (CMC, MP, PB), Laboratory Pol Bouin, Center Hospitalier Universitaire Maison Blanche, and Laboratory of Biochemistry (JCM), Faculty of Medicine, CNRS FRE 2260, IFR 53, Reims, France; and Laboratory of Tumor and Development Biology (AN, CG, PD, CM, AC, LV, JMF), University of Liège, Liège, Belgium

\begin{abstract}
SUMMARY: The basement membrane (BM) is the first barrier encountered by tumor cells when they become invasive. Moreover, some invasive tumor clusters are surrounded by a remnant or neosynthetized BM material. We have previously reported the presence of a particular $\alpha$ chain of type IV collagen, the $\alpha 3(\mathrm{IV})$ chain, in bronchopulmonary carcinomas. This chain was not detected in the normal bronchial epithelium, but was found around some invasive tumor cluster BM. In the present study, we examined the effects of the $\alpha 3$ (IV) chain on the invasive properties of bronchial tumor cell lines, with special emphasis on their expression of matrix metalloproteinase-2 (MMP-2) and its activator, membrane type 1-matrix metalloproteinase (MT1-MMP), which is largely involved in tumor progression. Two epithelial bronchial cell lines (16HBE14o- and BZR), showing different invasive abilities, were evaluated. Using the Boyden chamber invasion assay, we demonstrated that the $\alpha 3$ (IV) chain inhibits the invasive properties of BZR cells and modifies their morphology by inducing an epithelial cell shape. In the presence of the recombinant NC1 domain of the $\alpha 3$ (IV) chain, the expression of MMP-2 and tissue inhibitor of metalloproteinase-2 (TIMP-2) was not modified in either cell line. The NC1 $\alpha 3(\mathrm{IV})$ domain did not modulate the MT1-MMP expression of noninvasive 16HBE14ocells, whereas a 50\% decrease of MT1-MMP mRNA was observed in invasive BZR cells. Accordingly, Western blot analyses showed a disappearance of the 45-kd MT1-MMP form when BZR cells were treated with the recombinant NC1 $\alpha 3$ (IV) domain. These findings suggest that the $\alpha 3$ chain of type IV collagen may play a role in tumor invasion, at least by decreasing the expression and synthesis of MT1-MMP. (Lab Invest 2001, 81:167-175).
\end{abstract}

$D$ uring tumor progression, basement membrane (BM) architecture and composition are dramatically modified. This remodeling is a key step that involves both de novo synthesis at the invasive front and extensive degradation of BM components, including type IV collagen and laminins. Type IV collagen, the major structural component of BM, is a family of proteins composed of three helical isoforms. Six genetically distinct subunits are now described ( $\alpha 1$ through $\alpha 6$ ) (Butkowski et al, 1987; Hostikka et al, 1990, Zhou et al, 1993). Each chain is characterized by a long central Gly-X-Y domain, an amino-terminal $7 \mathrm{~S}$ domain, and a globular carboxy-terminal NC1 domain. Several studies have reported that biological activities triggered by the different $\alpha(\mathrm{IV})$ chains can be assigned to the specific NC1 domains of each chain (Chelberg et al, 1989; Monboisse et al, 1994). The most widely distributed form of collagen type IV is a heterotrimer

Received August 31, 2000.

Address reprint requests to: Dr. Myriam Polette, INSERM U514, IFR 53, Unit of Cellular Biology, Laboratory Pol Bouin, CHU Maison Blanche, 45, rue Cognacq-Jay, 51092 Reims, France.E-mail: myriam.polette@ univ-reims.fr composed of two $\alpha 1$ (IV) chains and one $\alpha 2$ (IV) chain (Kuhn, 1994; Yurchenco and Schittny, 1990). The other subunits ( $\alpha 3$ through $\alpha 6$ ) have a more restricted tissue distribution, which emphasizes a functional specificity of these six chains (Kahsai et al, 1997; Miner and Saus, 1994; Ninomiya et al, 1995; Zhou et al, 1993). Likewise, the $\alpha 3$ (IV) chain has been shown to be involved in several human pathologies, such as Goodpasture and Alport syndromes, in which mutations in the $\alpha 3$ (IV) chain gene were associated with a progressive nephropathy. Furthermore, type IV collagen $\alpha 3$-deficient mice have auditory and renal deficits related to alteration in BM structure and function (Cosgrove et al, 1998; Miner and Saus, 1996). Moreover, Monboisse et al (1994) have shown that the $\alpha 3$ (IV) chain prevents collagen type I-induced elastase and gelatinase secretion by human polymorphonuclear leukocytes (PMN), thereby decreasing their degradative properties. The $\alpha 3(\mathrm{IV})$ chain has also been involved in cancer pathologies. Petitclerc et al (2000) have recently demonstrated that the $\alpha 3$ (IV) domain inhibits tumor growth. Moreover, we have reported previously that the $\alpha 3$ (IV) chain is present in some tumor BM lining well-differentiated tumor clusters in 
bronchial cancers, whereas it is never detected in normal bronchi, suggesting a specific function of the $\alpha 3$ (IV) chain in tumor progression (Catusse et al, 2000; Polette et al, 1997).

BM degradation involves activation of matrix metalloproteinases (MMP), a family of zinc-dependent proteases that regulate proteolysis of most ECM components. Among these MMP, MMP-2, which preferentially degrades type IV collagen, has been largely implicated in the BM degradation associated with tumor invasion. MMP-2 overexpression has indeed been correlated with an invasive phenotype in numerous cancer types and in many tumor cell lines (Stetler-Stevenson, 1994). As are most MMP, MMP-2 is secreted as an inactive proenzyme and needs a proteolytic cleavage of the $\mathrm{N}$-terminal prodomain to become active. MMP-2 activation is a membrane-associated mechanism that requires the interaction of MMP-2 with TIMP-2 (tissue inhibitor of metalloproteinases-2) and MT1-MMP (membrane type 1-MMP) (Sato et al, 1994; Stetler-Stevenson, 1994). The MT1-MMP/TIMP 2 complex acts as a cell surface receptor for the C-terminal domain of MMP-2 (Strongin et al, 1995). Several reports have shown that overexpression of MT1-MMP, and thus an increase of MMP-2 activation, are correlated with an invasive phenotype (Gilles et al, 1996; Polette et al, 1998; Sato et al 1996). Although MT1-MMP is now considered as the main in vivo MMP-2 activator, many studies have demonstrated that MT1MMP can also exhibit intrinsic matrix-degrading activities. Indeed, MT1-MMP has been shown to digest gelatin, $\beta$ casein, $x$-elastin, fibronectin, vitronectin, $\beta$ chain of laminin and dermatan sulfate proteoglycan, native fibrillar type I, II, and III collagen, and laminin-5 (Imai et al, 1996; Koshikawa et al, 2000; Ohuchi et al, 1997; Pei and Weiss, 1996; Sato et al, 1996).

The aim of the present study is to examine the role of the $\alpha 3$ (IV) chain in bronchial tumor progression. We thus investigated the influence of the $\alpha 3$ (IV) chain on the migration and invasion of two bronchial carcinomas cell lines previously described as representing two different stages of bronchopulmonary tumor progression: 16HBE140-, a noninvasive bronchial cell line, and BZR, an invasive bronchial cell line. We also explored the effects of the $\alpha 3$ (IV) chain on degradative properties of both cell lines, focusing on the potential implication of MMP-2, MT1-MMP, and TIMP-2.

\section{Results}

\section{Morphology and Invasive Capacity of Bronchial Carcinomas Cell on Type IV Collagen}

To evaluate the influence of the $\alpha 3$ chain of type IV collagen on tumor cell invasiveness, we analyzed the invasive capacities of two bronchial cell lines in a modified Boyden chamber. In this assay, the upper surfaces of the filters were coated with human placenta (HP) type IV collagen containing the $\alpha 1$ (IV) and $\alpha 2$ (IV) chains or bovine lens capsule (BLC) type IV collagen containing the $\alpha 1$ (IV), $\alpha 2$ (IV), and $\alpha 3$ (IV) chains. 16HBE140 - cells did not display in vitro any invasive capacities, regardless of the coating used.
BZR cells demonstrated invasive behavior in Matrigel and HP (IV) collagen. In contrast, the BLC type collagen containing the $\alpha 3(\mathrm{IV})$ chain reduced the invasive capacity of BZR cells by approximately 11-fold as compared with the rate of invasion through $\mathrm{HP}$ (IV) collagen, which does not contain the $\alpha 3$ (IV) chain (Fig. 1A). We also compared the migration ability of BZR cells using peptides spanning different regions of the NC1 domain of the $\alpha 3$ (IV) chain. We used the $\alpha 3$ (IV) 185 to 203 and 185 to 191 peptides that contain the SNS triplet (residues 189 to 191) unique to the $\alpha 3$ (IV) chain and which have been shown previously to have biologic properties (Han et al, 1997). The $\alpha 3$ (IV) 194 to 203 peptide, which lacks the SNS triplet and has no described biologic effect, was used as peptide control in these migration experiments. When BZR cells were incubated with the $\alpha 3$ (IV) 194 to 203 peptide, tumor cell invasion was not inhibited, whereas the addition of

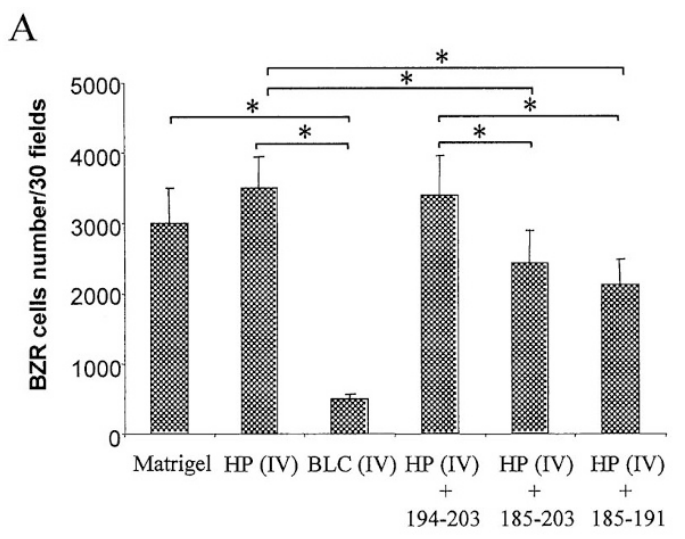

B
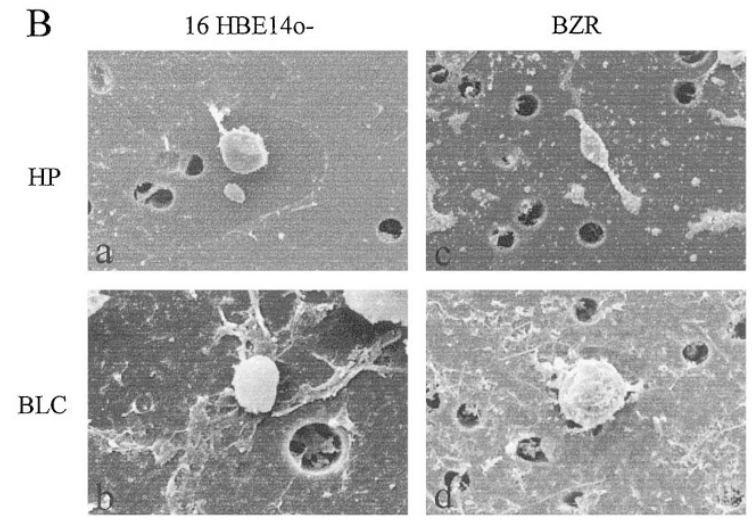

Figure 1

A, Effects of bovine lens capsule $(B L C)$ on BZR cell migration. BZR cells are layered on Matrigel, on human placenta (HP) type IV collagen, and on BLC type IV collagen. The $\alpha 3$ (IV) 185 to 203, 185 to 191 , and 194 to 203 peptides (10 $\mu \mathrm{g} / \mathrm{ml}$ ) were added to BZR cells layered on HP(IV). Each experiment was performed in triplicate and results are expressed as the mean of three different experiment \pm SEM. Thirty fields (original magnification, $\times 400$ ) were counted on each filter. ${ }^{*} p<0.05$. B, Morphological analyses by SEM of $16 \mathrm{HBEE} 140-$ and BZR cells in the modified chamber invasion assay: (a) 16HBE140 - cells layered on HP(IV) collagen; (b) 16HBE140 - cells layered on BLC(IV) collagen; (c) BZR cells layered on HP(IV) collagen; and (d) BZR cells layered on BLC(IV) collagen. a, c, d, original magnification, $\times 1200$; b, original magnification, $\times 3200$. 
the $\alpha 3$ (IV) 185 to 203 and 185 to 191 resulted in $31 \%$ and $37 \%$ inhibition of BZR cell invasion, respectively (Fig. 1A).

Cell morphology was also assessed by scanning electronic microscopy analyses in this assay. Regardless of the coating used, 16HBE140- cells displayed a rounded morphology characterizing an epithelioidlike phenotype (Fig. 1B). Invasive BZR cells, which progressively infiltrated the thin layer of type IV collagen, showed an elongated spindle cell morphology on HP(IV) collagen (Fig. 1B), but underwent important morphological changes when cultured on BLC collagen. Indeed, they lost their fibroblastic-like morphology and displayed the same rounded shape as noninvasive 16HBE140- cells (Fig. 1B).

These data suggest that the $\alpha 3$ (IV) chain could act on invasive cells by preventing the migration in a Boyden chamber, concomitant with important morphologic changes.

\section{Effect of the Recombinant NC1 $\alpha 3$ (IV) Domain on MMP mRNA Expression}

Because the malignant phenotype and matrix degradation largely involve MMP production, we investigated MMP synthesis after exposure of the two cell lines to the $\alpha 3$ (IV) chain. To clearly attribute the effect observed to the $\alpha 3$ (IV) chain, we used a recombinant protein corresponding to the NC1 domain of the $\alpha 1$ or $\alpha 3$ chains of type IV collagen. Both bronchial tumor cell lines were cultured for 48 hours in serum-free DMEM with $100 \mu \mathrm{g} / \mathrm{ml}$ of either NC1 $\alpha 1$ (IV) or NC1 $\alpha 3$ (IV) or with control buffer. Then, the expression of MMP-2, TIMP-2, and MT1-MMP was analyzed by Northern blotting (Fig. 2A) and RT-PCR analyses (Fig. 2C).

We found that invasive BZR cells expressed TIMP-2, MMP-2, and MT1-MMP mRNA (Fig. 2, A and C). TIMP-2 and MMP-2 mRNA expression were not significantly modified by the culture conditions. MT1MMP expression, in contrast, decreased significantly to approximately $50 \%$ when BZR cells were treated with the NC1 $\alpha 3$ (IV) domain (Fig. 2, B and D). Noninvasive 16HBE140 - cells did not express any MMP-2 mRNA (Fig. 2, A and C). MT1-MMP and TIMP-2 mRNA expression were detected in 16HBE140- but were not altered by the NC1 $\alpha 3$ (IV) domain when compared with treatment with the NC1 $\alpha 1$ (IV) domain or control buffer (Fig. 2, B and D).

\section{Effect of the Recombinant NC1 $\alpha 3$ (IV) Domain on MMP Protein Expression}

The effect of the NC1 domains on MMP-2 secretion was analyzed by gelatin zymography. BZR cells secreted MMP-2 in its latent 72-kd form whereas 16HBE140 - cells did not produce any detectable MMP-2. These patterns were not modified by the culture conditions (NC1 $\alpha 1$ [IV], NC1 $\alpha 3[\mathrm{IV}]$, or control) (Fig. 3A). The TIMP-2 levels were quantified by ELISA, which did not reveal any significant difference regardless of the culture conditions (Fig. 3B). MT1-MMP contained in BZR and 16HBE140- cell membrane extracts was analyzed by Western blot. Whatever the presence of exogenous MMP-2, we detected three major bands in control and NC1 $\alpha 1$ (IV)-treated cells (a doublet at $63 \mathrm{kd}$ and $60 \mathrm{kd}$ and one band at $45 \mathrm{kd}$ ) in BZR cells. The treatment with the NC1 $\alpha 3$ (IV) did not modify the level of the 63/60-kd doublet, but the 45-kd form was not detectable (Fig. 4A). MT1-MMP was found in its proenzyme 63-kd form in 16HBE14o- and this pattern was not modified by the culture conditions. To appreciate the consequences of the modified expression of MT1-MMP on the activation of MMP-2, exogenous pro-MMP-2 was added to the culture medium of both BZR and 16HBE140 - cell lines. The subsequent zymography analyses indicated no activation of exogenous MMP-2 in 16HBE14o- cells, whereas it revealed a decrease of the MMP-2 62-kd activated form, concomitant with the absence of MT1MMP 45-kd form when BZR cells were cultured with the recombinant NC1 $\alpha 3$ (IV) (Fig. 4B).

\section{Discussion}

In this study, we report that the $\alpha 3$ (IV) chain modulates the invasive behavior of human bronchial cells by regulating both at the transcriptional and posttranscriptional levels the MT1-MMP.

Using modified Boyden chambers, we showed that the $\alpha 3$ (IV) chain inhibited the invasive abilities of BZR cells. These observations could be correlated with those obtained by scanning electron microscopy. Indeed, when layered on HP type IV collagen, BZR cells displayed fibroblastic-like features, as well as filipodia and lamellipodia, attributes that have been largely associated with epithelial cell migration and/or invasion. In contrast, BZR cells became rounded when they were cultured in the presence of BLC type IV collagen and lost their migration-associated features. Furthermore, no effect of the $\alpha 3$ (IV) chain was observed on noninvasive 16HBE140 - cells strongly suggesting that the $\alpha 3$ (IV) chain has specific interactions with invasive tumor cells. These in vitro results may be related to our previous in vivo observations describing the presence of the $\alpha 3$ (IV) chain around the well differentiated clusters of squamous cell carcinomas and adenocarcinomas (Catusse et al, 2000). All of these data taken together suggest that the $\alpha 3$ (IV) chain has a limiting effect on tumor cell invasion. In this study, we also clearly showed that type IV collagen extracted from human placentas, containing exclusively the $\alpha 1$ and $\alpha 2$ chains, allowed the tumor cells to migrate. This observation was in agreement with other studies that have demonstrated that metastatic tumor cells adhere and exhibit motile behavior on the triple helical domain within $\alpha 1$ (IV) chain (Chelberg et al, 1989; Li et al, 1997). In the same way Matrigel, principally containing laminin, permitted the BZR cell invasion. These results are in agreement with many in vitro and in vivo observations reporting that laminin promotes the malignant phenotype (Fridman et al, 1991; Kim et al, 1994; Terranova et al, 1984). In light of these data, it can be postulated that interactions 
A

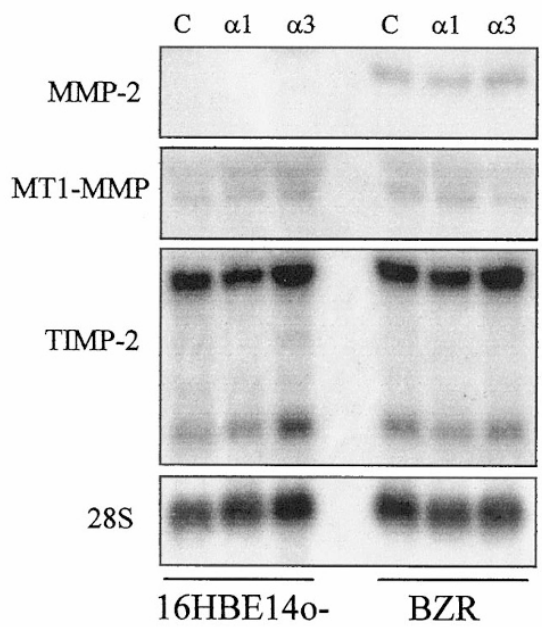

$\mathrm{C}$

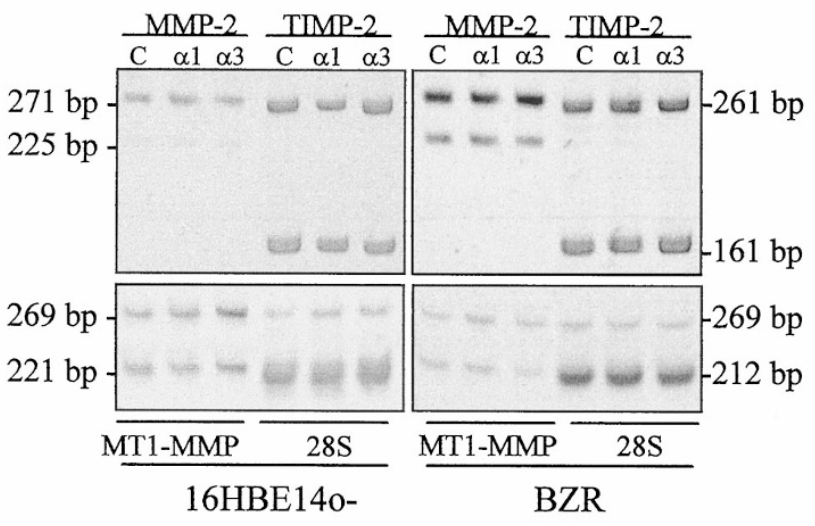

B

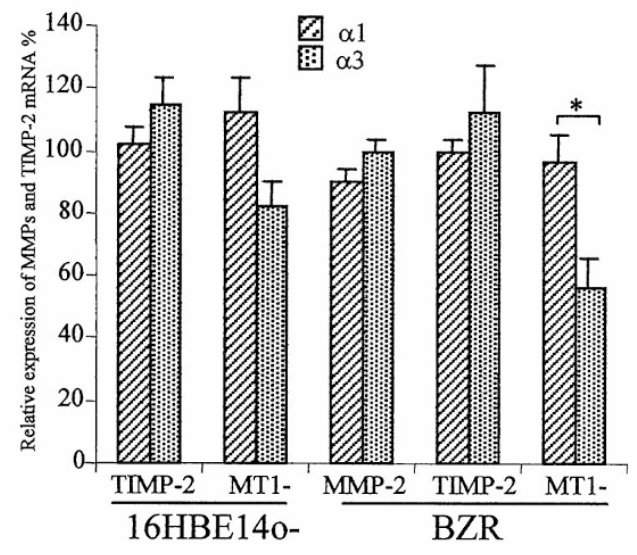

$\mathrm{D}$

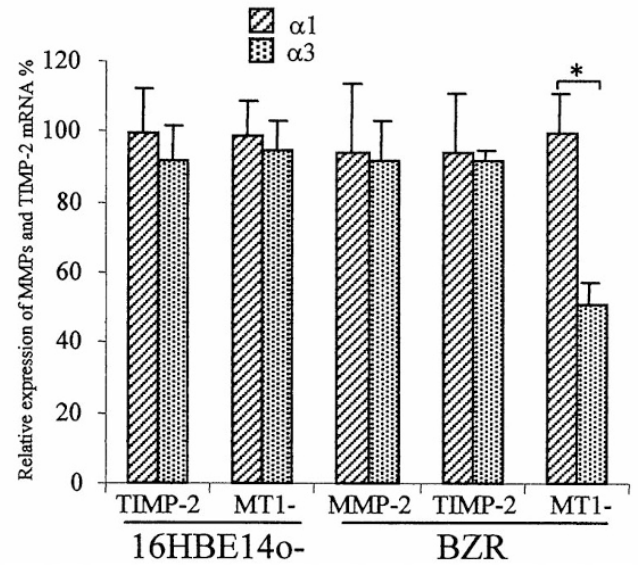

Figure 2.

Effect of the NC1 $\alpha 3$ (IV) on the expression of MMP-2, TIMP-2, and MT1-MMP by 16HBE140 - and BZR cells. Northern blotting and quantitative RT-PCR analyses of MMP-2, TIMP-2, and MT1-MMP mRNA were performed on total RNA extracted from BZR and 16HBE140- cells cultured with either the control buffer (C), the recombinant NC1 $\alpha 1$ (IV) domain ( $\alpha 1$ ), or the recombinant NC1 $\alpha 3$ (IV) domain ( $\alpha 3$ ). A, MT1-MMP mRNA of $4.5 \mathrm{~kb}$ and TIMP-2 mRNA of $3.8 \mathrm{~kb}$ and $1.2 \mathrm{~kb}$ were clearly detected in 16HBE140 - and BZR cells. MMP-2 (3.2 kb) was only found in BZR cell lines. B, The relative expression of MMP-2, MT1-MMP, and TIMP-2 mRNA were normalized with 36B4 level. C, Endogenous MMP-2, TIMP-2, MT1-MMP, and 28S bands were detected at the expected sizes (225 bp, 161 bp, 221 bp, and 212 bp, respectively). pCTR01 control bands for MMP-2, TIMP-2, MT1-MMP, and $28 \mathrm{~S}$ were obtained at the expected sizes (271 bp, $261 \mathrm{bp}, 269 \mathrm{bp}$, and $269 \mathrm{bp}$, respectively). D, MMP-2, TIMP-2, MT1-MMP, and 28S were expressed as a ratio to its specific internal control. The levels of mRNA were normalized with $28 \mathrm{~S}$ level. The results are expressed as a percentage of control. * $p<0.05$.

between tumor cells and BM components, such as the ubiquitous $\alpha 1$ (IV) chain of type IV collagen or laminin, favor the tridimensional migration of invasive cells. On the other hand, the $\alpha 3$ chain of type IV collagen significantly impedes the invasive capacities of the tumor cells.

Because MMP-2 expression has been reported to be involved in tumor cell invasion in most bronchopulmonary cancers (Nawrocki et al, 1997), we studied the regulation of MMP-2, MT1-MMP (its activator), and TIMP-2 (its specific inhibitor) by the NC1 domain of the $\alpha 3$ (IV) chain in two bronchial cell lines. We observed that the recombinant NC1 $\alpha 3$ (IV) domain decreased MT1-MMP mRNA and protein expression in BZR cells, but did not modify the mRNA and protein expression of TIMP-2 and MMP-2. Accordingly, Pasco et al (2000) have recently shown a down-regulation of MMP ex- pression by the $\alpha 3(\mathrm{IV})$ chain in sarcomatous cells. In agreement with our data, modulation of MMP expression by ECM components has been previously documented. Indeed, Gilles et al (1998) have reported an increase of MMP-2 activation in response to secreted protein, acidic, rich in cysteine (SPARC). Similarly, fibrillar collagen type I, when embedded in threedimensional gel, has been shown to modulate the synthesis and activation of MMP-2 by enhancing MT1-MMP expression (Gilles et al, 1997; Kurschat et al, 1999). Moreover, Gilles et al (1997) have reported that collagen type I induces MT1-MMP expression in invasive breast carcinoma cell lines but not in the noninvasive counterparts. In contrast to the ECM molecules cited above, we demonstrated here that the $\alpha 3$ (IV) chain has a negative effect on MT1-MMP mRNA expression in invasive bronchial BZR cells. Moreover, 
A

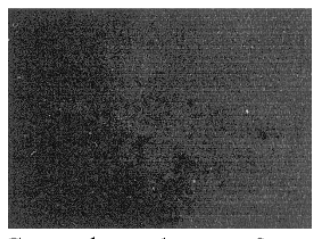

Control $\alpha 1 \quad \alpha 3$

16HBE140-

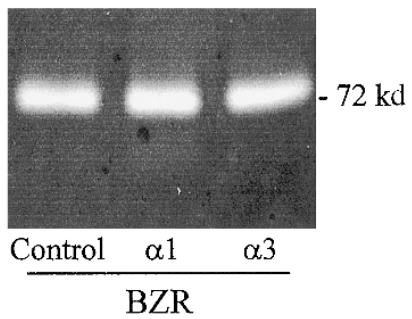

BZR
B

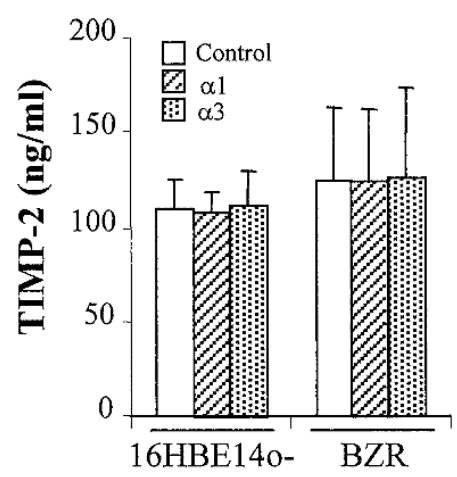

Figure 3.

MMP-2 and TIMP-2 protein expression by BZR and 16HBE140 - cell lines. A, Analyses of gelatinolytic activities in the conditioned media of BZR and 16HBE140 - cells cultured with either the control buffer, the recombinant NC1 $\alpha 1$ (IV) domain ( $\alpha 1$ ), or the recombinant NC1 $\alpha 3$ (IV) domain $(\alpha 3)$. Results showed the 72-kd latent form of MMP-2 in BZR cells. B, Quantification of TIMP-2 released in culture media of BZR and 16HBE140 - cells cultured in presence of either the control buffer, the recombinant NC1 $\alpha 1$ (IV) protein $(\alpha 1)$, or the recombinant NC1 $\alpha 3$ (IV) protein ( $\alpha 3)$. TIMP-2 concentrations were determined by ELISA.

the regulation of MT1-MMP mRNA expression by the recombinant NC1 $\alpha 3$ (IV) domain seems to be specific to invasive cells because we did not observe any modification of MT1-MMP expression and activation in noninvasive 16HBE140 - cells treated with the recombinant NC1 $\alpha 3(\mathrm{IV})$ domain. Taken together, these results suggest that the NC1 $\alpha 3$ (IV) domain has specific interactions with invasive tumor cells leading to a decrease of MT1-MMP expression.

We also observed a potential post-transcriptional regulation of MT1-MMP by the NC1 $\alpha 3$ (IV) domain in invasive BZR cells. Indeed, MT1-MMP Western blot analysis showed that treatment with the NC1 $\alpha 3$ (IV) domain did not modify the level of the 63/60-kd doublet, whereas it abolished the 45-kd form. This MT1-MMP 45-kd form has been previously characterized as a N-terminal-truncated MT1-MMP lacking its active site and has been reported as a byproduct of MMPdependent proteolysis of the 60-kd active form of MT1MMP (Lohi et al, 1996; Stanton et al, 1998). Although the exact role of the 45-kd processed form of MT1-MMP is not known, several studies have shown that the MT1MMP 45-kd form is correlated to MMP-2 activation (Lohi et al, 1996; Stanton et al, 1998). Accordingly, we also
A

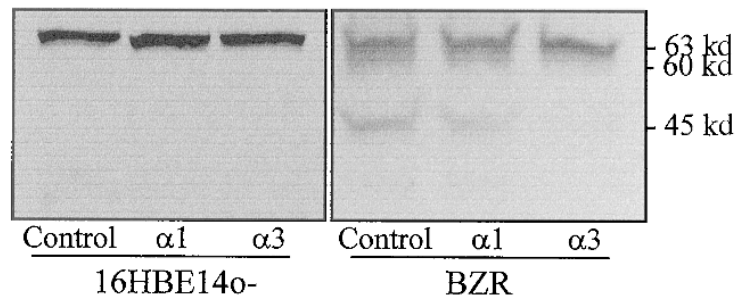

B

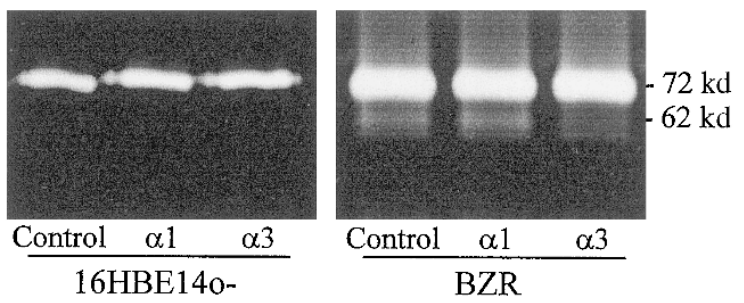

Figure 4

Processing of MMP-2 to its active form is correlated with presence of the 45-kd form of MT1-MMP. A, Detection of MT1-MMP in BZR and 16HBE140cells extracts by Western blotting analyses. The anti-MT1-MMP antibody recognized three major bands of $63 \mathrm{kd}, 60 \mathrm{kd}$, and $45 \mathrm{kd}$ in the NC1 $\alpha 1$ (IV) $(\alpha 1)$ - or the buffer control-treated BZR cells. The anti-MT1-MMP antibody detected only two bands of $63 \mathrm{kd}$ and $60 \mathrm{kd}$ in the NC1 $\alpha 3$ (IV) $(\alpha 3)$-treated BZR cells. 16HBE140 - cells only expressed the 63-kd form of MT1-MMP. B, Zymography analyses of exogenous MMP-2 activation. Results showed two forms (the latent 72-kd form and the active 62-kd form) of MMP-2 when BZR cells were cultured with the recombinant NC1 $\alpha 1$ (IV) domain $(\alpha 1)$ or the buffer control. One form of MMP-2 (72 kd) was detected when BZR cells were cultured with the recombinant NC1 $\alpha 3$ (IV) $(\alpha 3)$. 16HBE140 - were not able to activate pro-MMP2, regardless of the culture conditions. The results shown are representative of three experiments.

showed here that the absence of 45-kd form was associated with a decrease in the MMP-2 activation. Previous reports have demonstrated that MT1-MMP-mediated pro-MMP-2 activation at the cell surface depends on the TIMP-2 concentration (Butler et al, 1998). Indeed, at low concentrations, TIMP-2 increases MMP-2 activation by forming an MT1-MMP/TIMP-2 complex available for MMP-2 binding, whereas at high concentrations, TIMP-2 binds all free active MT1-MMP molecules needed to activate pro-MMP-2. Thus, the balance between TIMP-2 and MT1-MMP determines the activation status of MMP-2. In this study, we showed that the NC1 $\alpha 3$ (IV) reduced MT1-MMP expression and did not modify TIMP-2 expression in invasive BZR cells. A relative excess of TIMP-2 could reduce the amount of free active MT1-MMP present at the cell surface of invasive BZR cells, thereby preventing activation of pro-MMP-2. These results suggest that the NC1 domain of the $\alpha 3$ (IV) chain could decrease the tumor cell invasive behavior by regulating MMP-2 activation via MT1-MMP synthesis and processing. In addition to being implicated in metastatic progression via its role in MMP-2 activation, recent observations have described that MT1-MMP itself displays the ability to degrade several matrix components (Imai et al, 1996; Koshikawa et al, 2000; Ohuchi 
et al, 1997; Pei and Weiss, 1996; Sato et al, 1996). Because the amount of pro-MMP-2 in its active 62-kd form was not impressive in invasive BZR cells, we cannot exclude the possibility that MT1-MMP is directly responsible for BZR cell migration independently of MMP-2 activity. Thus, the down-regulation of MT1-MMP by the $\alpha 3$ (IV) chain could also have a direct effect on the tumor invasion process by decreasing ECM degradation mediated by MT1-MMP.

In conclusion, these results demonstrate that the $\alpha 3$ chain of type IV collagen, present in tumor neosynthesized BM, by acting on MT1-MMP expression could limit cancer progression.

\section{Materials and Methods}

\section{Cell Lines and Culture}

The human bronchial cells lines, 16HBE140- and BZR, were derived from normal bronchial cells immortalized after transfection with the SV40 large T-antigen. BZR cell line was also infected with the $v$ - Ha ras oncogene. The cells were cultured at $37^{\circ} \mathrm{C}$ and $5 \% \mathrm{CO}_{2}$ in DMEM (Gibco BRL, Paisley, Scotland) supplemented with penicillin streptomycin $(50 \mathrm{ng} / \mathrm{ml})$ and 10\% FCS (Gibco BRL).

\section{Boyden Chamber Invasion Assay}

The in vitro invasiveness of cell lines was assessed by using a modified chamber assay. Cells $\left(10^{5}\right)$ were suspended in $800 \mu$ l of DMEM supplemented with $0.2 \%$ BSA (Sigma, St Louis, Missouri) and layered in the upper compartment of the chamber (Nucleopore, Pleasanton, California). The lower compartment of the chamber was filled with $200 \mu$ l of DMEM supplemented with 10\% FCS and 2\% BSA. The two compartments were separated with a porous filter $(8 \mu \mathrm{m}$ pore, Nucleopore) coated with either $25 \mu \mathrm{g} /$ filter of type IV collagen extracted from human placenta (Sigma) that contains the $\alpha 1$ and $\alpha 2$ chains only, or 25 $\mu \mathrm{g} /$ filter of type IV collagen extracted from BLC that contains the $\alpha 1, \alpha 2$, and $\alpha 3$ chains, prepared as previously described (Monboisse et al, 1994), or coated with $25 \mu \mathrm{g} /$ filter Matrigel obtained from the Engelbrecht-Holm-Swarm (EHS) tumor. Moreover, to assess the specific effect of the $\alpha 3(\mathrm{IV})$ chain on BZR migration, BZR tumor cells deposited onto membranes coated with HP(IV), were incubated with peptides corresponding to the residues 185 to 203,185 to 191 , and 194 to 203 of the NC1 domain of the $\alpha 3$ (IV) chain (Cybergene, St Malo, France). The chambers were incubated for 5 hours at $37^{\circ} \mathrm{C}$. The filters were then fixed in cold methanol at $-20^{\circ} \mathrm{C}$ for 10 minutes and stained with hematoxylin for 2 minutes. The cells on top of the filter were wiped away with a cotton swab. Quantification of the invasion was performed by counting the number of the cells at the lower surface of the filters (30 fields at $400 \times$ magnification). Each cell line was tested three times and each experiment was performed in triplicate. Scanning electron microscopic observation was also performed on the different coated filters. For this purpose, $10^{4}$ cells were incubated in the upper compartment of the chamber for 2 hours. The filters were fixed in $2.5 \%$ glutaraldehyde, dehydrated in a gradient of ethanol, critical point-dried, and observed with an XL 30 Philips scanning electron microscope.

\section{Purification of the Recombinant NC1 Domain-GST Fusion Proteins}

The construction of pGEX 2T expression vectors carrying cDNA encoding the $\alpha 1$ (IV) or $\alpha 3$ (IV) NC1 domainsGST fusion proteins was described by Dehan et al (1996). Expression in Escherichia coli JM1 01 cells were carried out as described by Smith and Johnson (1988). Fusion proteins were present in inclusion bodies. The insoluble cell pellet from bacterial cultures were sonicated three times for 2 minutes and centrifuged (8000 $\times g, 10$ minutes, $4^{\circ} \mathrm{C}$ ) in $40 \mathrm{~mm}$ Tris, $\mathrm{pH}$ 8.0. The final pellet was solubilized in $50 \mathrm{~mm}$ Tris, $\mathrm{pH}$ 8.0, containing 8 $\mathrm{M}$ urea and $1 \% \beta$-mercaptoethanol. The mixture was then fractionated by column chromatography (PD 10 Sephadex G25, Pharmacia, Uppsala, Sweden) previously equilibrated in $50 \mathrm{~mm}$ Tris, $\mathrm{pH} 8.8$, at $4^{\circ} \mathrm{C}$. After overnight storage at $4^{\circ} \mathrm{C}$, the fusion proteins were affinity-purified on glutathione-Sepharose (Pharmacia) and eluted with an excess of reduced glutathione (Boehringer Mannheim, Germany). The free glutathione was removed on a PD 10 Sephadex G25 column equilibrated in PBS. Aliquots of fusion proteins taken at all steps of the purification process were reduced and subjected to a $10 \%$ SDS polyacrylamide gel electrophoresis. The gels were stained with $0.1 \%$ Coomassie Brilliant Blue R-250 in 40\% methanol and 10\% acetic acid, then destained in $10 \%$ acetic acid and $20 \%$ methanol.

\section{Preparation of Serum-Free Conditioned Media}

Cells were plated in 6 -well plates $(400,000$ cells/well) for 48 hours in DMEM/FCS. The cells were next washed twice with serum-free DMEM and were incubated for 48 hours in serum-free medium (SFM) containing the recombinant NC1 domains $(100 \mu \mathrm{g} / \mathrm{ml})$ or control buffer (Tris, pH 8.8, $40 \mathrm{~mm}$ ). For MMP-2 activation analysis, the culture media were incubated in SFM/MMP-2 (SFM and SFM conditioned for 48 hours by MMP-2-transfected $\mathrm{CHO}$ as a source of exogenous MMP-2) mixture containing the recombinant NC1 domains $(100 \mu \mathrm{g} / \mathrm{ml})$ or control buffer. The conditioned media were collected for zymography and/or TIMP-2 ELISA analyses (see below). Cultures were set up in triplicate and experiments were repeated at least three times. The number of cells per flask was determined by cell counting.

\section{Northern Blotting Analyses}

Total RNA was extracted from both cell lines cultivated in SFM containing the recombinant NC1 ( $\alpha 1$ or $\alpha 3$ ) domains or control buffer as described above. After 48 hours, the conditioned media were collected for zymographic and/or for TIMP-2 analyses, and the cells were collected for Northern blotting and RT-PCR 
analyses. RNA extraction was performed with RNA Miniprep kits used as recommended by the manufacturer (Qiagen, Hilden, Germany). Six-microgram samples of each RNA were analyzed by electrophoresis in $1 \%$ agarose gels containing $10 \%$ formaldehyde and transferred onto nylon membranes (Hybond-N; Amersham, Buckinghamshire, United Kingdom). The membranes were hybridized with cDNA probes for MMP-2 (1600 bp, kindly provided by Dr. G. Murphy, Cambridge, United Kingdom), MT1-MMP (1700 bp, kindly provided by Dr. Seiki, Kanazawa University, Japan), TIMP-2 (1035 bp, kindly provided by Dr. Y. De Clerck, Los Angeles, California) labeled with ${ }^{32} \mathrm{P}$ using random labeling kit (Amersham). The RNA loading was normalized using the 36B4 probe. The signals were quantified by fluorometric scanning (LAS-1000, Fuji).

\section{RT-PCR Analyses}

RT-PCR was performed using $10 \mathrm{ng}$ of total RNA. An internal control RNA template, pCTR01, was introduced in each sample to monitor the assays of MMP-2, MT1-MMP, TIMP-2, and $28 \mathrm{~S}\left(5.10^{4}, 2.10^{4}, 2.10^{4}\right.$, and $4.10^{6}$ copies, respectively). RT-PCR was performed using the GeneAmp Thermostable RNA PCR Kit (Perkin-Elmer, Foster City, California) and for pairs of oligonucleotides (Eurogentec, Seraing, Belgium). Forward and reverse primers for human MMP-2, MT1-MMP, TIMP-2, and 28S were designed as follows: MMP-2 primers (forward 5'-GGCTGGTCAGTGGCTTGGGGTA-3', reverse 5'-AGATCTTCTTCTTCAAGGACCGGTT-3'), MT1-MMP primers (forward 5'CCATTGGGCATCCAGAAGAGAGC3', reverse 5'-GGATACCCAATGCCCATTGGCCA-3'), TIMP-2 primers (forward 5'-GTCATCTTGATCTCAT-AACGCTGG-3', reverse 5'-AGCCCATCTGTACCTGTGGTTCA-3'), and $28 \mathrm{~S}$ primers (forward 5'-GTTCACCCACTAATAGGGAACGTGA-3', reverse 5'-GGATTCTGACTTAGAGGCGT TCAGT-3'). Reverse transcription was performed at $70^{\circ} \mathrm{C}$ for 15 minutes, followed by a 2-minute incubation at $95^{\circ} \mathrm{C}$ for denaturation of RNA-DNA heteroduplexes. Amplification was started by 15 seconds at $94^{\circ} \mathrm{C}, 15$ seconds at $68^{\circ} \mathrm{C}, 10$ seconds at $72^{\circ} \mathrm{C}$ (30 cycles for MMP-2, MT1MMP, and TIMP-2, and 17 cycles for $28 \mathrm{~S}$ ), and terminated by 2 minutes at $72^{\circ} \mathrm{C}$. RT-PCR products were separated by acrylamide gel electrophoresis, stained with Gelstar (FMC, Bioproducts, Rockland, Maine), and quantified by fluorometric scanning (LAS-1000, Fuji). The expected sizes for MMP-2, MT1-MMP, and TIMP-2 are 271 bp, 269 bp, and $261 \mathrm{bp}$, respectively, for the pCTR01; and $225 \mathrm{bp}, 221$ bp, and $161 \mathrm{bp}$, respectively, for the endogenous mRNA. The expected size for the $28 \mathrm{~S}$ is $269 \mathrm{bp}$ for the pCRT01 and 212 bp for the endogenous rRNA.

\section{Preparation of Cell Lysates}

Confluent BZR cells were cultured in six-well plates with either $100 \mu \mathrm{g} / \mathrm{ml}$ recombinant NC1 $\alpha 1$ (IV) domain, $100 \mu \mathrm{g} / \mathrm{ml}$ recombinant NC1 $\alpha 3$ (IV) domain, or the control buffer in SFM or in SFM/MMP-2 for 48 hours. The conditioned media were stored at $-20^{\circ} \mathrm{C}$ and were analyzed by gelatin zymography and the cells were reserved for protein extraction. The cells were washed twice with PBS (Gibco BRL) and lysed with lysis buffer $(0.15 \mathrm{~m} \mathrm{NaCl}, 1 \%$ sodium deoxycholate, $1 \%$ Triton $\mathrm{X}-100,0.1 \%$ SDS, $0.1 \mathrm{M}$ Tris- $\mathrm{HCl} \mathrm{pH} 7.4$, 1\% NP 40, 5 mm lodoacetamide, 1 mm PMSF) for 30 minutes at $4^{\circ} \mathrm{C}$. Cell lysates were aspirated with a 21-gauge needle and centrifuged at $12,500 \times g$ for 10 minutes at $4^{\circ} \mathrm{C}$. The supernatant was stored at $-20^{\circ} \mathrm{C}$ until used. Sample were analyzed by Western blot. Amounts of proteins were evaluated with the DC Protein Assay kit (BioRad, Hercules, California).

\section{Gelatin Zymography Assays}

Samples were diluted 1:2 in a Laemmli buffer (BioRad) and were separated on a $10 \%$ SDS polyacrylamide gel containing $1 \mathrm{mg} / \mathrm{ml}$ gelatin. SDS was removed from the gel with $2 \%$ triton $\mathrm{X}-100$ washes. The gels were incubated overnight at $37^{\circ} \mathrm{C}$ in $50 \mathrm{~mm}$ Tris $\mathrm{pH} 7.6,5$ $\mathrm{mm} \mathrm{CaCl}_{2}$, and $0.1 \%$ Triton $\mathrm{X}-100$, and stained with $0.1 \%$ Coomassie Brilliant Blue R-250 in 40\% methanol and $10 \%$ acetic acid, then destained in $10 \%$ acetic acid and $20 \%$ methanol. The proteolytic activities were quantified from gels by densitometric scanning (LAS-1000, Fuji).

\section{TIMP-2 ELISA}

After overnight coating with rabbit-anti-TIMP-2 antibody (1:750) (Gilles et al, 1998) at $4^{\circ} \mathrm{C}, 96$-well ELISA plates were washed with $0.1 \mathrm{~m}$ PBS, 3\% BSA, 0.05\% Tween 20 , and incubated with $50 \mu \mathrm{l}$ of conditioned media samples or pure TIMP-2 (0.31 to $20 \mathrm{ng} / \mathrm{ml})$ for 2 hours at $37^{\circ} \mathrm{C}$. After repeated washes with $0.1 \mathrm{M}$ PBS, and $0.01 \%$ Tween 20, 96-well ELISA plates were incubated with chicken anti-TIMP-2 antibody (1:200) (Gilles et al, 1998) for 2 hours at room temperature, washed, and incubated with peroxidase-coupled swine antichicken antibody $(1: 10,000)$ in PBS-BSA-Tween 20 for 1 hour at room temperature. Absorbance was read at $405 \mathrm{~nm}$ after incubation of 96-well ELISA plates with 2,2'-azino-bis[ethylbenthiazoline-6-sulfonic acid] (ABTS) (Sigma) solution supplemented with $\mathrm{H}_{2} \mathrm{O}_{2}$.

\section{Western Blotting Analyses}

Twenty micrograms of proteins from cells lysates were mixed 1:2 with Laemmli buffer (BioRad) containing 5\% $\beta$-mercaptoethanol ( $\mathrm{v} / \mathrm{v})$, boiled for 5 minutes, separated on a $10 \%$ SDS-PAGE gel, and transferred to a nitrocellulose filter (Hybond-C Extra, Amersham, Buckinghamshire, United Kingdom). Transfer was performed at $120 \mathrm{~V}$ for 1 hour. The membrane was blocked with $0.1 \%$ Tween 20 and 5\% milk in PBS 2 hours at room temperature before exposure with the 4MMP-3H3 antibody (1:10, a generous gift from Dr. M. C. Rio, Strasbourg, France) overnight at $4^{\circ} \mathrm{C}$. The membranes were incubated with a secondary biotinylated sheep-antimouse antibody (1:1500; Amersham, Arlington Heights, Illinois) for 1 hour at room temperature and then with the streptavidin-peroxidase complex (1:1500; Amersham) for 30 minutes. Immunoreactive protein bands were detected with ECL Plus Western blotting reagents (Amersham). 


\section{Statistical Analyses}

Data are expressed as means $\pm \mathrm{SD}$. Student's $t$ test was used to compare the invasive ability of the cells and both expression and synthesis levels of MMP-2, MT1-MMP, and TIMP-2 under various experimental conditions. $p<0.05$ was considered significant.

\section{Acknowledgements}

We thank Dr. M. C. Rio (Strasbourg, France) for providing the anti-MT1-MMP antibody, Drs. G. Murphy, M. Seiki, and Y. De Clerck for providing the cDNA probes of MMP-2, MT1-MMP, and TIMP-2, respectively, and Drs. D. Gruenert and C. Harris for providing the 16HBE140 - and BZR human bronchial cell lines, respectively. This work was supported financially by the ARERS and the Lions Club of Soissons and Villers-Cotterets, France.

\section{References}

Butkowski RJ, Langeveld JP, Wieslander J, Hamilton J, and Hudson BG (1987). Localization of the Goodpasture epitope to a novel chain of basement membrane collagen. J Biol Chem 262:7874-7877.

Butler GS, Butler MJ, Atkinson SJ, Will H, Tamura T, Schade van Westrum S, Crabbe T, Clements J, d'Ortho MP, and Murphy G (1998). The TIMP2 membrane type I metalloproteinase receptor regulates the concentration and efficient activation of gelatinase A. A kinetic study. J Biol Chem 273:871-880.

Catusse $\mathrm{C}$, Polette $\mathrm{M}$, Coraux $\mathrm{C}$, Burlet $\mathrm{H}$, and Birembaut $\mathrm{P}$ (2000). Modified basement membrane composition during bronchopulmonary tumor progression. J Histochem Cytochem 48:663-669.

Chelberg MK, Tsilibary EC, Hauser AR, and McCarthy JB (1989). Type IV collagen-mediated melanoma cell adhesion and migration: Involvement of multiple, distinct domains of the collagen molecule. Cancer Res 49:4796-4802.

Cosgrove D, Samuelson G, Meehan DT, Miller C, McGee J, Walsh E, and Siegel M (1998). Ultrastructural, physiological, and molecular defects in the inner ear of a gene-knockout mouse model for autosomal Alport syndrome. Hear Res 121:84-98.

Dehan P, Weber M, Zhang Xu, Reeders ST, Foidart JM, and Tryggvason K (1996). Sera from patients with anti-GBM nephritis including Goodpasture syndrome show heterogenous reactivity to recombinant NC1 domain of type IV collagen $\alpha$ chains. Nephrol Dial Transplant 11:2215-2222.

Fridman R, Kibbey MC, Royce LS, Zain M, and Sweeney TM (1991). Enhanced tumor growth of both primary and established human and murine tumor cells in athymic mice after coinjection with Matrigel. J Natl Cancer Inst 83:769-774.

Gilles C, Bassuk JA, Pulyaeva H, Sage EH, Foidart JM, and Thompson EW (1998). Sparc/octeonectin induces matrix metalloproteinase 2 activation in human breast cancer cell lines. Cancer Res 58:5529-5536.

Gilles C, Polette M, Piette J, Munaut C, Thompson EW, Birembaut $P$, and Foidart JM (1996). High level of MT-MMP expression is associated with invasiveness of cervical cancer cells. Int J Cancer 65:209-213.
Gilles C, Polette M, Seiki M, Birembaut P, and Thompson EW (1997). Implication of collagen type I-induced membranetype 1-metalloproteinase expression and matrix metalloproteinase- 2 activation in the metastatic progression of breast carcinoma. Lab Invest 76:651-660.

Han J, Ohno N, Pasco S, Monboisse JC, Borel JP, Kefalides NA (1997). A cell binding domain from the $\alpha 3$ chain of type IV collagen inhibits proliferation of melanoma cells. J Biol Chem 272:20395-20401.

Hostikka SL, Eddy RL, Byers MG, Hoyhtya M, Shows TB, and Tryggvason K (1990). Identification of a distinct type IV collagen $\alpha$ chain with restricted kidney distribution and assignment of its gene to the locus of $X$ chromosome-linked Alport syndrome. Proc Natl Acad Sci USA 87:1606-1610.

Imai K, Ohuchi E, Aoki T, Nomura H, Fujii Y, Sato H, Seiki M, and Okada $Y$ (1996). Membrane type matrix metalloproteinase 1 is a gelatinolytic enzyme and is secreted in a complex with tissue inhibitor of metalloproteinase 2. Cancer Res 56:2707-2710.

Kahsai TZ, Enders GC, Gunwar S, Brunmarks C, Wieslander J, Kalluri R, Zhou J, Noelken ME, and Hudson BG (1997). Seminiferous tubule basement membrane. J Biol Chem 272: 17023-17032.

Kim WH, Jun SH, Kibbey MC, Thompson EW, and Kleiman HK (1994). Expression of $\beta 1$ integrin in lamin-adhesionselected human colon cancer cell lines of varying tumorigenicity. Invasion Metastasis 14:147-155.

Koshikawa N, Gianelli G, Cirulli V, Miyazaki K, and Quaranta $\checkmark$ (2000). Role of cell surface MT1-MMP in epithelial cell migration over laminin-5. J Cell Biol 148:615-624.

Kuhn K (1994). Basement membrane (type IV) collagen. Matrix Biol 14:439-445.

Kurschat $P$, Zigrino $P$, Nischt R, Breitkopf $K$, Steurer $P$, Klein CE, Krieg T, and Mauch C (1999). Tissue inhibitor of matrix metalloproteinase-2 regulates matrix metalloproteinase-2 activation by modulation of membrane-type 1 matrix metalloproteinase activity in high and low invasive melanoma cell lines. J Biol Chem 274:21056-21062.

Li C, McCarthy JB, Furcht LT, and Fields GB (1997). An all-D amino acid peptide model of $\alpha 1$ (IV)531-543 from type IV collagen binds the $\alpha 3 \beta 1$ integrin and mediates tumor cell adhesion, spreading and motility. Biochemistry 36:15404-15410.

Lohi J, Lehti K, Westermarck J, Kahari VM, and Keski-Oja J (1996). Regulation of membrane-type matrix metalloproteinase- 1 expression by growth factors and phorbol 12-myristate 13-acetate. Eur J Biochem 239:239-247.

Miner JH and Saus JR (1994). Collagen $\alpha 3, \alpha 4$ and $\alpha 5$ chains in rodent BL: Sequence, distribution, association with laminins and developmental switches. J Cell Biol 121:879-891.

Miner JH and Saus JR (1996). Molecular and functional defects in Kidneys of mice lacking collagen $\alpha 3(\mathrm{IV})$ : Implication for Alport syndrome. J Cell Biol 135:1403-1413.

Monboisse JC, Garnotel R, Bellon G, Ohno N, Perreau C, Borel JP, and Kefalides NA (1994). The $\alpha 3$ chain of type IV collagen prevents activation of human polymorphonuclear leukocytes. J Biol Chem 269:25475-25482.

Nawrocki B, Polette M, Marchand V, Monteau M, Gillery P, Tournier JM, and Birembaut P (1997). Expression of matrix metalloproteinases and their inhibitors in human bronchopulmonary carcinomas: Quantitative and morphological analyses. Int J Cancer 72:556-564. 
Ninomiya Y, Kagawa M, Iyama, KI, Naito I, Kishiro Y, Seyer J, Sugimoto M, Oohashi T, and Sado Y (1995). Differential expression of two basement membrane collagen genes COL4A6 and COL4A5, demonstrated by immunofluorescence staining using peptide-specific monoclonal antibodies. J Cell Biol 130:1219-1229.

Ohuchi E, Imai K, Fujii Y, Sato H, Seiki M, and Okada $Y$ (1997). Membrane type matrix metalloproteinase digests interstitial collagen and other extracellular matrix macromolecules. J Biol Chem 272:2446-2451.

Pasco S, Han J, Gillery P, Bellon G, Maquart FX, Borel JP, Kefalides NA, and Monboisse JC (2000). A specific sequence of the noncollagenous domain of the $\alpha 3$ (IV) chain of type IV collagen inhibits expression and activation of matrix metalloproteinases by tumor cells. Cancer Res 60:467-473.

Pei D and Weiss SJ (1996). Transmembrane-deletion mutants of the membrane type matrix metalloproteinase- 1 process progelatinase $A$ and express intrinsic matrix-degrading activity. J Biol Chem 271:9135-9140.

Petitclerc E, Boutaud A, Prestayko A, Xu J, Sado Y, Ninomiya Y, Sarras MP, Hudson BG, and Brooks PC (2000). New functions for non-collagenous domains of human collagen type IV. J Biol Chem 275:8051-8061.

Polette M, Gilles C, de Bentzmann S, Gruenert D, Tournier JM, and Birembaut P (1998). Association of fibroblastoid features with the invasive phenotype in human bronchial cancer cell lines. Clin Exp Metastasis 16:105-112.

Polette M, Thiblet J, Ploton D, Buisson AC, Monboisse JC, Tournier JM, and Birembaut P (1997). Distribution of $\alpha 1$ (IV) and $\alpha 3$ (IV) chains of type IV collagen in lung tumours. J Pathol 182:185-191.

Sato H, Kinoshita T, Takino T, Nakayama K, and Seiki M (1996). Activation of a recombinant membrane type 1-matrix metalloproteinase (MT1-MMP) by furin and its interaction with tissue inhibitor of metalloproteinases (TIMP-2). FEBS Lett 393:101-104.
Sato H, Takino T, Okada Y, Cao J, Shinagawa A, Yamamoto E, and Seiki M (1994). A matrix metalloproteinase expressed on the surface of invasive tumor cells. Nature 370:61-65.

Smith DB and Johnson KS (1988). Single-step purification of polypeptides expressed in Escherichia coli in fusions with glutathione S-transferase. Gene 67:31-40.

Stanton H, Gavrilovic J, Atkinson ST, d'Ortho MP, Yamada KM, Zardi L, and Murphy G (1998). The activation of proMMP-2 (gelatinase A) by HT1080 fibrosarcoma cells is promoted by culture on a fibronectin substrate and is concomitant with an increase in processing of MT1-MMT (MMP14) to a $45 \mathrm{kDa}$ form. J Cell Sci 111:2789-2798.

Stetler-Stevenson WG (1994). Progelatinase activation during tumor cell invasion. Invasion Metastasis 14:259-268.

Strongin AY, Colloer I, Bannikov G, Marmer BL, Grant GA, and Goldberg GI (1995). Mechanism of cell surface activation of 72-Kda type IV collagenase. J Biol Chem 270:5331-5338.

Terranova VP, Williams JE, Liotta LA, and Martin GR (1984). Modulation of the metastatic activity of melanoma cells by laminin and fibronectin. Science 226:982-985.

Yurchenco PD and Schittny JC (1990). Molecular architecture of basement membranes. FASEB J 4:1577-1590.

Zhou J, Machizuki T, Smeets H, Antignac C, Laurila P, de Paepe A, Tryggvason K, and Reeders ST (1993). Deletion of the paired $\alpha 5$ (IV) and $\alpha 6$ (IV) collagen genes in inherited smooth muscle tumors. Science 261:1167-1169. 